\title{
Juxtaductal coarctation with type B dissection of the aorta: A new operative technique
}

\author{
Anil Bhan, MCh, Saket Agarwal, MS, Rajesh Sharma, MCh, and Pannangipalli Venugopal, MCh, New Delhi, India
}

$\mathrm{T}$ he combination of coarctation of the aorta with dissection proximal to the coarctation (type A dissection) ${ }^{1}$ has often been reported, especially in association with Turner syndrome. ${ }^{2}$ However, a combination of coarctation of the aorta and a type B dissection, although a known entity, is not frequently reported. ${ }^{3-5}$ The management of these patients is technically difficult because of the large amount of collateral flow into this segment of aorta. It becomes all the more difficult because of the older age of these patients. ${ }^{3,4}$ We used a new operative technique in treating one such patient.

\section{Clinical Summary}

A 32-year-old man reported having had low back pain for 2 years, dyspnea on exertion (New York Heart Association class II) for 1 year, and occasional tingling and numbness in the left lower limb. He had no history of motor weakness, impotence, intermittent claudication, or urinary or bowel symptoms. The patient had systemic hypertension of 5 years' duration controlled by medication.

On examination, he was well built, with no pallor, cyanosis, or pedal edema. His spine and long bones showed no abnormalities. Bilateral upper limb pulses were bounding whereas lower limb pulses were not palpable. The jugular venous pressure was within normal limits. Blood pressure in both upper limbs was 150/96 mm $\mathrm{Hg}$ whereas blood pressure in lower limbs was not recordable. An early diastolic decrescendo murmur was audible in the second and third intercostal spaces in the left parasternal area. Aortic pulsations were palpable in the epigastrium and umbilical area.

A plain chest radiograph revealed a prominent aortic arch and a left ventricular apex with a cardiothoracic ratio of 0.6. An electrocardiogram showed normal sinus rhythm with left axis deviation, and an echocardiogram showed an enlarged and hypertrophied left ventricle with a dilated aortic root and moderately severe aortic regurgitation. Other valves were normal.

From the Cardiothoracic Sciences Centre, All India Institute of Medical Sciences, Ansari Nagar, New Delhi, India.

Received for publication July 27, 2001; accepted for publication Aug 3, 2001.

Address for reprints: Anil Bhan, MCh, Additional Professor, Cardiothoracic \& Vascular Surgery, Cardiothoracic Sciences Centre, All India Institute of Medical Sciences, Ansari Nagar, New Delhi, 110029, India (E-mail: anilbhan@hotmail.com).

J Thorac Cardiovasc Surg 2002; 123:365-7

Copyright (C) 2002 by The American Association for Thoracic Surgery $0022-5223 / 2002 \$ 35.00+0 \quad \mathbf{1 2 / 5 4 / 1 1 9 3 3 2}$

doi:10.1067/mtc.2002.119332

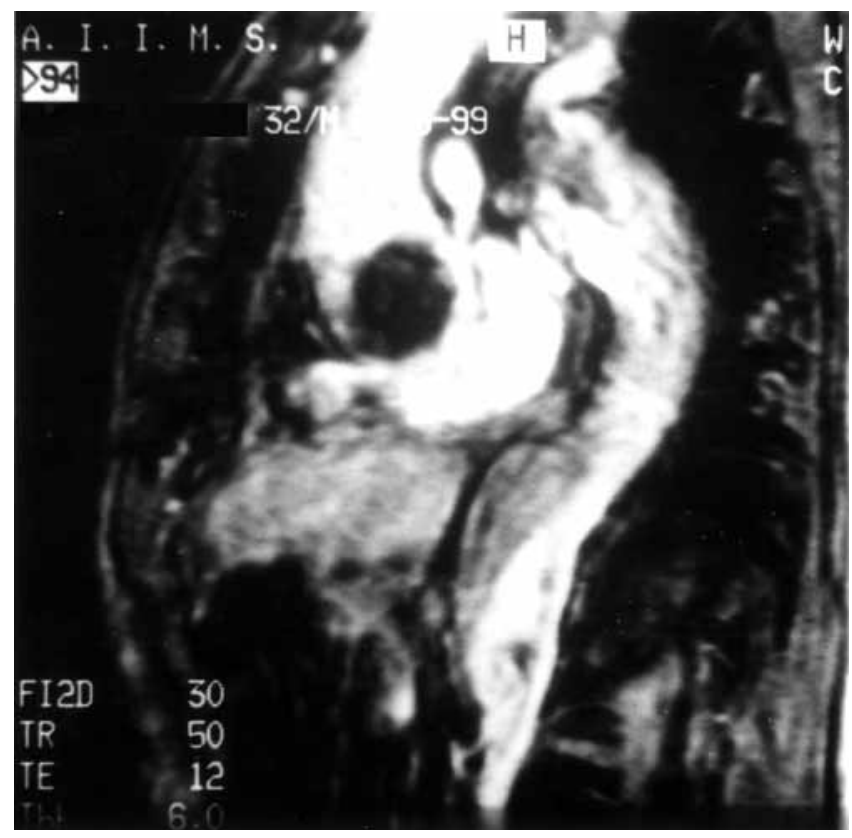

Figure 1. Sagittal oblique cine magnetic resonance image of the aorta showing postductal coarctation. The descending aorta beyond the coarctated segment shows type B dissection.

Magnetic resonance imaging showed coarctation of aorta just beyond the origin of the left subclavian artery (Figures 1 and 2). Distal to the coarctation, there was a dissection of the aorta with the dissection flap extending to the renal arteries.

\section{Operative Technique}

The patient was operated on through a posterolateral thoracotomy in the fifth left intercostal space. Findings were a coarctation of the aorta in the usual position below the left subclavian artery. External appearance was suggestive of dissection of the aorta below the coarctated segment up to the supraceliac aorta. The left subclavian artery was large and the aortic arch was within the normal size range. The coarctated segment was mobilized. The aorta was transected just distal to the left subclavian artery after proximal clamping, and the proximal cut end was anastomosed to a 20mm Meadox vascular graft (Boston Scientific, Meadox Medicals, Inc, Oakland, NJ). The distal cut end of the aorta was suture closed. The collateral inflow into this segment was significant and hence kept perfusing the spinal arteries even in the absence of ante- 


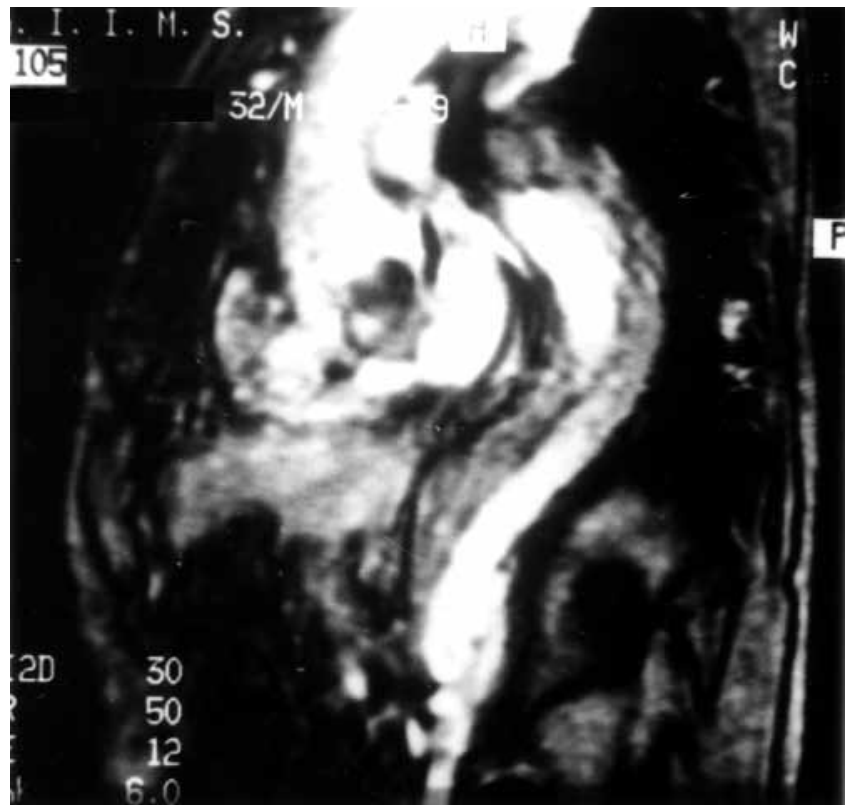

Figure 2. Sagittal oblique cine magnetic resonance image of the aorta showing the coarctated segment. The descending thoracic aorta shows evidence of an intimal flap with differential flow within the true and false lumina. Signal void is seen at the root of the aorta during diastole, suggestive of aortic regurgitation.

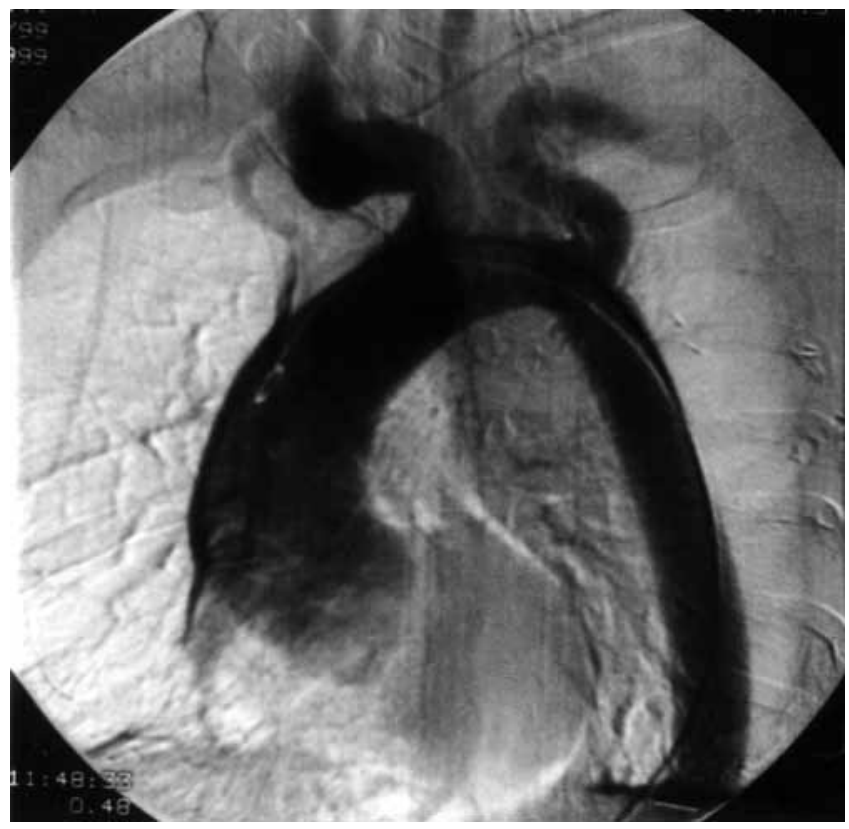

Figure 3. Postoperative intra-arterial digital subtraction angiogram of the aorta shows good reconstruction with no anastomotic narrowing and good distal flow. No evidence of contrast leak is seen.

grade flow, serving the functional purpose of "left heart bypass." Inasmuch as the collateral inflow into the distal aorta was torrential, the lower portion of the aorta had to be controlled while the

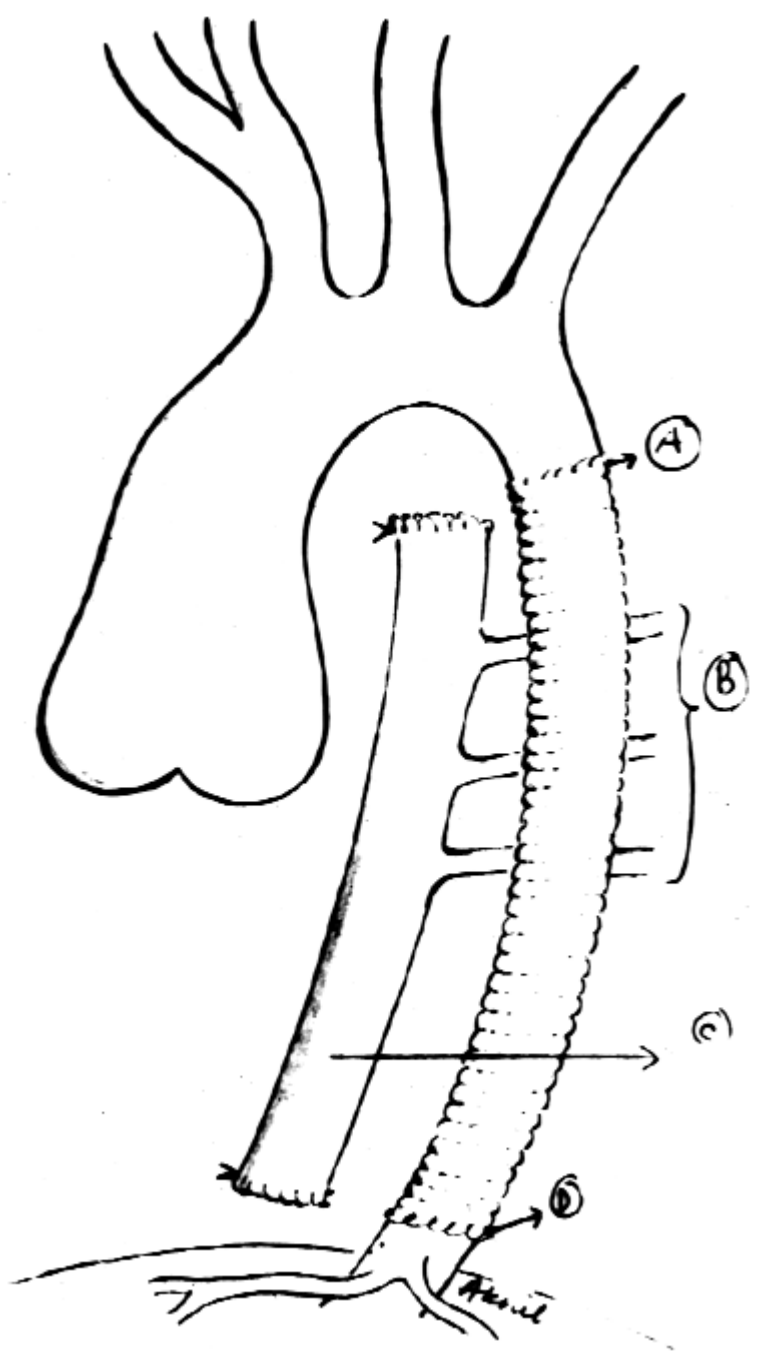

Figure 4. Diagrammatic representation of the operation showing the excluded segment of aorta with massive inflow collaterals and the graft in situ. $A$, Proximal anastomosis; $B$, inflow collaterals; $C$, excluded segment of aorta; $D$, distal anastomosis with reconstructed cuff.

distal anastomosis was being created. An abdominal incision was therefore made to control the supraceliac aorta.

The descending thoracic aorta was divided just above the diaphragm. The proximal cut end was suture closed and the distal end was anastomosed to the vascular graft in an end-to-end fashion after shaping a distal cuff constituted by the conjoined layers of aorta.

The patient had an uneventful recovery, and 2 months after the procedure he underwent aortic valve replacement for aortic regurgitation. At 12 months of follow-up he was doing well on a regimen of oral anticoagulants. A follow-up intra-arterial digital subtraction angiogram done at 12 months showed a patent graft with no flow into the excluded native aorta. No collateral vessels could be visualized (Figure 3). 


\section{Discussion}

Surgical experience with coarctation of the aorta with distal aortic dissection has been scant. ${ }^{3,4,6}$ Borst, Heinemann, and Stone ${ }^{7}$ performed simultaneous relief of the coarctation with concomitant replacement of the aorta from the subclavian artery to the mid thoracic level in one patient. Details of the operative techniques were not available.

The difficulty in this patient was the existence of massive inflow collaterals into the distal aorta. These collaterals were large because of the age of the patient. It was technically almost impossible to control all the collaterals, and opening the aorta would have meant life-threatening bleeding. Total hypothermic circulatory arrest in this patient was not technically feasible because of moderate aortic regurgitation with the risk of left ventricular distention on ventricular fibrillation. The new procedure described herein was to perform a proximal anastomosis excluding the coarctated segment with an aortic clamp and overrunning the distal end of the transected aorta. The aorta was transected at the level of the aortic hiatus, beyond which the aorta was of normal size, although dissected. The graft was sutured distally to the transected aorta and the proximal stump of the distal transected aorta was overrun. This left us with a blind aortic segment from distal to the coarctated segment up to the aortic hiatus, with multiple collaterals flowing into this blind segment of aorta. We had two major concerns: (1) expansion of this segment with resultant rupture and (2) acute paraplegia.

Expansion of the blind segment with resultant rupture. Besides being concerned about expansion and rupture of the blind segment, we also anticipated thrombosis of the entire blind pouch, because there was no outflow for the blood except the spinal arteries. The follow-up digital subtraction angiogram revealed that the entire sac had thrombosed although the graft was functioning well.

Acute paraplegia. The operation was based on the premise that collateral inflow into this blind pouch would be sufficient to maintain the spinal flow. As the distal runoff from the collateral inflow was insufficient, the sac gradually thrombosed and the spinal circulation probably collateralized during this time.

The literature available on this rare pathologic combination is scant. We have offered a new surgical technique with a possible physiologic basis.

\section{References}

1. Anagnostopoulos CE. Classification. In: Anagnostopoulos CE, editor: Acute aortic dissections. Baltimore: University Park Press; 1975.

2. Weytjens C, Bove T, Van Der Nepen P. Aortic dissection and Turner's syndrome. J Cardiovasc Surg (Torino). 2000;41:295-7.

3. Yamaguchi A, Adachi H, Kamio H, Murata S, Okada M, Adachi K, et al. A combination of preductal aortic coarctation and type B dissection: report of a case. Surg Today. 1998;28:435-7.

4. Beitzke A, Stein JI, Gamillscheg A, Rigler B. Dissection of the descending aorta after balloon angioplasty of native coarctation. Pediatr Cardiol. 1997;18:222-5.

5. Zaslow J, Krasnoff SO. Coarctation of the thoracic aorta with an aneurysm distal to the obstruction: report of a case. Am Heart J. 1943; 26:832.

6. Svensson LG. Management of acute aortic dissection associated with coarctation by a single operation. Ann Thorac Surg. 1994;58:241-3.

7. Borst HG, Heinemann MK, Stone CD. In: Surgical treatment of aortic dissection. London: Churchill Livingstone; 1996. p. 278. 